Japanese Journal of Applied Physics, 26 (2) (1987) 239-245

\title{
Laser-Induced Fluorescence and Optical Reflection Spectra of J apanese Natural Dyes on Silk
}

Tadaki Miyoshi and Yasunori Matsuda ${ }^{1}$

Technical College, Yamaguchi U niversity, Tokiwadai, U be, Yamaguchi 755

${ }^{1}$ Pearl Research laboratory, K. MIKIMOTO \& Co., Ltd., Aobadai, M eguro-ku, Tokyo 153

(Received June 12, 1986; accepted November 22, 1986)

Fluorescence spectra under nitrogen-laser excitation were measured for silk cloth dyed with Japanese natural dyes. An identification of the dyes on silk was carried out using a laser-induced fluorescence (LIF) technique since dyed cloth has a characteristic fluorescence spectra. Moreover, it is possible to identify dyes on faded cloth and on cloth prepared by a combination dyeing using two kinds of dyes. The LIF technique can identify dyes on cloth which is difficult to identify using the reflection spectral method. 


\section{$\S 1$. Introduction}

The identification of the natural dyes on textile fabrics has artistic, historical and archaeological values. Thus, it is important to study regarding cultural history, especially the history of dyeing and weaving manufacturers, as well as for the preservation and restoration of textiles. ${ }^{1,2)}$ If we have various types of information concerning the relation between dyes and the period during which they were used, it may provide information concerning the customs and manners of that period. Furthermore, the collection of relevant data may allow a discussion of the technological history of dyeing and weaving, as well as infering the period when an interesting textile to be analyzed was dyed.

The scientific method for identifying dyes on textiles can generally be divided into two groups in the light of the experimental procedures. One group comprises a socalled destructive method. It is explained that dyes on textiles are extracted with a suitable solvent; then, the extract is investigated with various analytical techniques such as a traditional chemical analysis, ${ }^{3)}$ thin-layer chromatography, ${ }^{4-6)}$ solution spectrophotometry in the visible and ultraviolet regions, ${ }^{7-9)}$ infrared absorption spectroscopy ${ }^{10)}$ and other chromatographical techniques. ${ }^{11)}$ Although a combination of these technique can accomplish a more accurate identification of dyes, these destructive techniques have a considerable drawback in that a valuable specimen is destroyed by the extraction even if the required amount is extremely small. On the other hand, a nondestructive method which uses no extraction step has been studied in Japan, since extraction has not tended to be permitted officially in recent years. As a nondestructive method, optical reflection spectra (spectral reflectance curves), ${ }^{12}$ fluorescence observation under a mercury lamp excitation ${ }^{13)}$ and fluorescence spectra under a xenon lamp excitation ${ }^{14)}$ have been reported. The optical reflection spectral method can be applied to identify dyes with various spectral characteristics similar to the dyes of a respective period, since the identification is based on a comparison of spectra. However, this method is inferior to the destructive method described above regarding accuracy. Moreover, a large specimen is difficult to analyze, since a sample chamber is needed.

In recent years, a laser-induced fluorescence (LIF) technique has been used to investigate the physical properties of materials. It is known that inorganic pigments and synthetic dyes show a characteristic fluorescence. ${ }^{15)}$ Therefore, it is possible to identify 
the colouring materials constituted with inorganic pigments and synthetic dyes by measuring the fluorescence spectra. The LIF technique has been already applied in order to identify pigments in oil colours; it has been reported to be more sensitive than an ordinary fluorescence method. ${ }^{16)}$ Although fluorescence is observed in most of the pigments in oil colours using a nitrogen laser, fluorescence has been detected in only a few pigments using a mercury lamp as an excitation source. ${ }^{17)}$

In this paper, we report on the fluorescence spectra of Japanese natural dyes on silk cloths and dyed cloths after fading caused by exposure to light; we did this because textile fabrics having art historical and archaeological value become partly or wholly fade in most cases. ${ }^{18)}$ Comparisons between the LIF technique and the ordinary fluorescence method are described for some dyed silk cloths. The advantages of the LIF technique are that they are nondestructive, sensitive and capable of measuring very small or large specimens. Reflection spectra of the dyed cloths were also measured in order to compare with the LIF technique.

\section{§2. Experimental Procedure}

Samples in the present study were modern silk cloth dyed with natural dyes (Table I) using traditional Japanese techniques; scarlet or green tint on silk was prepared by combination dyeing. First, silk cloth was dyed red or blue, respectively; it was then dyed yellow. The dyes, except for cochineal, were produced from vegetables and had been used in Japan until synthetic dyes came into use during the 19th century; cochineal is a well-known insect dye. Natural dyes generally fall into two main groups: dyes applied directly to fibres and not requiring a dyeing assistant (a so-called mordant) and dyes used with a mordant, forming a complex with the dye molecule on fibres. The former group in this study consists of the Amur cork-tree, gardenia and indigo. On the other hand, alum was used as a mordant for sappanwood and cochineal, plant ash for safflower, kariyasu and shikon, and citric acid for turmeric. A quantitative description of the concentration of dyes and an identification of the decomposition products are difficult for such cloth since dyebath contains a high concentration of impurities originating from vegetables (or cochineal insect) and mordant.

Figure 1 shows the experimental arrangement for the LIF technique. The LIF spectra were measured at $300 \mathrm{~K}$ using a nitrogen laser (NDC JS-1000L; wavelength $\lambda=$ 
$337.1 \mathrm{~nm}$, pulse duration $=5 \mathrm{~ns}$, repetition rate $=4 \mathrm{~Hz}$ ). The laser beam was set at about $50^{\circ}$ off the normal incidence to the plane of the sample and was focused on a spot about $1 \mathrm{~mm}^{2}$ in area by a quartz lens (focal length $\mathrm{f}=150 \mathrm{~mm}$, diameter $\mathrm{d}=40 \mathrm{~mm}$ ). The peak power density of the laser light on the sample surface was regulated to be about 50 $\mathrm{kW} / \mathrm{cm}^{2}$ using neutral density filters. The sample was held between a board and an $\mathrm{Al}$ plate with a hole $6 \mathrm{~mm}$ in diameter. The laser beam and fluorescence passed through the hole. Fluorescence was observed at $90^{\circ}$ to the laser beam and was focused on the entrance slit of a 50-cm monochromator (Oyo Bunko ASI-50S) by a glass lens ( $\mathrm{f}=70$ $\mathrm{mm}, \mathrm{d}=40 \mathrm{~mm}$ ). A glass filter (Toshiba L-39) was used to eliminate any scattered light from the laser beam. Time-integrated fluorescence spectra were observed with a monochromator, a photomultiplier (Hamamatsu R955), a boxcar integrator (homemade) and a recorder. Ordinary fluorescence spectra were also measured using a high-pressure mercury lamp (Toshiba SHL-100UV; electric power $=100 \mathrm{~W}, \lambda=365 \mathrm{~nm}$ ) with a glass filter (Toshiba UV-D2), in order to make a comparison with the LIF spectra.

Optical reflection spectra were measured with a double-beam spectrophotometer equipped with an integrating sphere (Japan Spectroscopic UVIDEC-610C). Fading experiments were performed with a xenon fademeter (Suga Test Instruments XF-1). Silk samples were irradiated with a high-pressure xenon lamp (electric power $=1.5 \mathrm{~kW}$ ) under the condition of JIS (Japanese Industrial Standard) L-0843. The values of the CIE colour difference were measured using a colour-difference meter (Nippon Denshoku Kogyo ND-1001DP).

\section{§3. Results and Discussion}

We now compare the LIF spectra with the ordinary fluorescence spectra before discussing the spectra of dyes on silk cloths. Figure 2 shows the ordinary fluorescence spectra for red dyes on silk under mercury lamp excitation. Although these spectra are similar to that under laser excitation (Figs. 4(a) and 6(a)), the relative intensity of fluorescence at $500 \mathrm{~nm}$ for sappanwood is about two-times larger under the mercury lamp excitation than under the nitrogen-laser excitation. The difference is considered to be due to the influence of stray light from the mercury lamp. While the fluorescence intensity depends on the samples, the intensity of stray light is almost independent of the samples. Since the fluorescence intensity for sappanwood is weaker than that for 
safflower, stray light is not negligible under mercury lamp excitation; it appears as background light in the spectrum. A similar result can also be observed for cochineal, whose fluorescence intensity is about half of that for sappanwood. These results indicate that the LIF technique is more sensitive than the ordinary fluorescence method for dyes on silk.

The LIF spectra are shown in Figs. 3(a)-13(a). The peak intensity ratio and the peak wavelength are listed in Table II. Two fluorescence bands constitute most of the LIF spectra of dyed silk samples. One band near $430 \mathrm{~nm}$ is considered to be assigned to silk fibres and the other band at the longer-wavelength region to the dye. Fluorescence from an undyed silk cloth was measured to confirm the assignment (Fig. 3(a)). A fluorescence band was observed at $430 \mathrm{~nm}$ before an exposure. The fluorescence band shifts to a longer wavelength and the peak intensity decreases after the exposure. Figure 3(b) shows the optical reflection spectra for an undyed silk cloth before and after exposure. Reflectance at shorter wavelengths $(\lambda \leq 480 \mathrm{~nm})$ decrease after exposure. The spectral changes are attributable to a deterioration of silk fibres owing to the exposure to intense light.

Fluorescence and reflection spectra of dyes on silk samples, except for indigo and shikon, are discussed in the following. Under this experimental condition, indigo shows no fluorescence and shikon shows very weak fluorescence.

\subsection{Red and yellow dyes on silk}

Figures 4(a)-10(a) represent fluorescence spectra for red and yellow dyes on silk before and after fading caused by exposure to intense light; the exposure time and the CIE colour difference, $\Delta \mathrm{E}$, are listed in Table III. Fluorescence from dye at longer wavelength decreases upon increasing the exposure time; also, the peak shifts to a shorter wavelength. On the other hand, fluorescence from silk fibres at $430 \mathrm{~nm}$ increases upon increasing the exposure time and the peak shifts to a shorter wavelength. These results could be explained by the following processes. Since dye molecules are decomposed in part by exposure to intense light, the fluorescence from the dye decreases. Since the fluorescence of a dye in the shorter-wavelength side and the fluorescence of silk fibres are absorbed with the dye itself and the reabsorption decreases with the decomposition, both of the fluorescence peaks shift to shorter 
wavelength after fading. An additional band appears around $500 \mathrm{~nm}$ after fading for sappanwood (Fig. 4(a)). The additional band is considered to be attributable to decomposition products of the dye molecules. It is interesting that the fluorescence band for cochineal near $640 \mathrm{~nm}$ increases according to the exposure (Fig. 5 (a)). This result is explained by the decomposition of impurities in the dye with the exposure to the intense light, which quench the fluorescence from the dye. The impurities may originate from the cochineal insect, since alum is pure.

Figures 4(b)-10(b) show the reflection spectra for the red and yellow dyes on silk before and after fading. It can be seen that the reflectance is low at shorter wavelengths and high at longer wavelengths before fading. The reflectance at shorter wavelengths increases upon increasing the exposure time. This result can be explained according to the decrease in the optical absorption due to the decomposition of dye molecules.

Safflower on silk has the poorest light stability among the red dyes in the present study. While fluorescence from dyes is observed in a faded sample with $\Delta \mathrm{E}=37.6$ (exposure time $=20 \mathrm{~h})$, it is not observed in a sample with $\Delta \mathrm{E}=47.9$ (exposure time $=$ $44 \mathrm{~h}$ ) as shown in Fig. 6(a). Thus, the LIF technique can be used to identify dyes for faded cloths with $\Delta \mathrm{E} \leq 35$. On the other hand, an identification by the reflection spectra is difficult, especially for a faded sample with $\Delta \mathrm{E} \geq 30$. Therefore, the LIF technique is more useful than the reflection method for faded samples. Other dyes also show similar results.

\subsection{Scarlet tint on silk}

Figure 11 shows the fluorescence and reflection spectra of a silk sample prepared by combination dyeing of sappanwood and yellow dyes, such as Amur cork-tree and turmeric. The fluorescence bands near $600 \mathrm{~nm}$ are attributable to sappanwood, $530 \mathrm{~nm}$ band (solid curve) to Amur cork-tree and $540 \mathrm{~nm}$ band (dashed curve) to turmeric. Comparing this spectrum with the spectrum for sappanwood (Fig. 4(a)), the fluorescence peak from sappanwood shifts to a shorter wavelength and the peak intensity increases. It is considered that these results are due to combination dyeing, since fluorescence from sappanwood is overlapped with that from Amur cork-tree or turmeric.

Figure 12 represents the fluorescence and reflection spectra of a silk sample prepared 
by combination dyeing of safflower and yellow dyes: Amur cork-tree, turmeric and gardenia. The fluorescence bands at about $600 \mathrm{~nm}$ are attributable to safflower, $520 \mathrm{~nm}$ band (solid curve) to Amur cork-tree, 510nm band (dashed curve) to turmeric and 430 $\mathrm{nm}$ band (dashed-and-dotted curve) to silk fibre; fluorescence from gardenia cannot be detected in the sample dyed with safflower and gardenia. Fluorescence peaks of Amur cork-tree and turmeric shift to shorter wavelengths, compared with the respective fluorescence peaks of silk samples dyed with a single dye. This shift can be explained according to the following process: fluorescence of Amur cork tree (or turmeric) in the longer wavelength side is absorbed with safflower, so that the peak shifts to a shorter wavelength.

The fluorescence bands of Amur cork tree and turmeric can be observed in Figs. 11(a) and 12(a). On the other hand, the spectral features of the yellow dyes in reflection spectra can hardly be observed in Figs. 11(b) and 12(b), since the red dyes reduce reflectance at short wavelengths $(\lambda \leq 600 \mathrm{~nm})$, where the spectral features of the yellow dyes appear.

An identification of the red and yellow dyes is possible in some silk samples dyed scarlet tint. On the other hand, it is difficult to distinguish sappanwood from safflower on silk prepared by combination dyeing of Amur cork tree with these red dyes.

\subsection{Green tint on silk}

Figure 13 shows the fluorescence and reflection spectra of a silk sample dyed with a combination of indigo and yellow dyes: Amur cork-tree (solid curves), kariyasu (dashed curves) and gardenia (dash-and-dotted curves). Indigo has generally been used as a blue dye, since the dye has been easily obtained from ancient times. The reflection spectrum for indigo on silk is shown in Fig. 13(b) (dotted curve).

Only the fluorescence band from yellow dye can be observed in Fig. 13(a), since indigo shows no fluorescence. Consequently, the yellow dyes are identified with the LIF technique, but indigo is not. On the other hand, the yellow dyes are difficult to identify with the reflection method, but indigo is. Thus, an identification of green tint can be performed with a combination of the LIF technique and the reflection method. 
The possibility of identifying various dyes which originate in nature on textile fabrics is examined using the LIF technique and the reflection spectral method. The authors find that most of the silk samples coloured with a single dye show specific fluorescence bands. Furthermore, the fluorescence can be detected in faded samples which are difficult to identify by the reflection spectral method. In addition to this result, several silk samples prepared by a combination dyeing of two kinds of dyes show characteristic bands originating from the dyes. Thus, an identification of dyes on silk is performed nondestructively using the LIF technique; this is more useful than the reflection method, especially for faded samples and samples prepared by combination dyeing.

In the present paper, we have mentioned a part of the natural dyes used in ancient Japan. Other dyes, which are not mentioned, are also important regarding the history of dyeing and weaving manufactures. Therefore, further studies will be undertaken on the dyes using the LIF technique. Moreover, the fluorescence from a modified textile with a mordant and the effect of a dye complex with a mordant on the fluorescence will be also investigated and reported elsewhere.

\section{Acknowledgement}

We are grateful to Prof. R. Sugisita of Tokyo National University of Fine Arts and Music for valuable suggestions and for his help in obtaining some dyed silk samples. 


\section{References}

1) R. J. Forbes: Studies in Ancient Technology (Brill, Leiden, 1965) 2nd ed., Vo1.3, p. 99.

2) J. M. Diehl: Textile Conservation, ed. J. E. Leene (Butterworth, London, 1972) P. 23.

3) K. Hayashi: Proc. 2nd Int. Symp. Conservation and Restoration of Cultural Property, Tokyo and Tsukuba, 1978 (I nternational Symposium Proceedings, Inc., Tokyo, 1978) p. 39.

4) L. Masschelein-Kleiner: Mikrochem, Acta 6 (1967) 1080.

5) L. Masschelein-Kleiner and J. B. Heylen: Stud. Conserv. 13 (1968) 87.

6) H. Schweppe: Z. Anal. Chem. 276 (1975) 291.

7) M. Salzman, A. M. Keay and J. Christensen: Dyestuffs 44 (1963) 241.

8) M. Salzman: Archaeological Chemistry II, Advances in Chemistry Series 171 (American Chemical Society, Washington DC, 1978) p. 172.

9) G. W. Taylor: Stud. Conserv. 28 (1983) 153.

10) D. H. Abrahams and S. M. Edelstein: Am. Dyest. Rep. 53 (1964) 19.

11) J. Wouters: Stud. Conserv. 30 (1985) 119.

12) M. Kashiwagi: Kokogaku to Shizenkagaku 14 (1981) 39 [in Japanese].

13) K. Hayashi and G. Suzushino: Scientific Papers on Japanese Antiques and Art Crafts $3(1952) 36$.

14) Y. Nasu, F. Nakazawa and M. Kashiwagi: Kokogaku to Shizenkagaku 16 (1983) 105 [in Japanese].

15) C. N. R. Rao: Ultra-Violet and Visible Spectroscopy (Butterworth, London, 1967).

16) T. Miyoshi, M. Ikeya, S. Kinoshita and T. Kushida: Jpn. J. Appl. Phys. 21 (1982) 1032.

17) E. R. de la Rie: Stud. Conserv. 27 (1982) 1.

18) D. G. Duff, R. S. Sinclair and D. Stirling: Stud. Conserv. 22 (1977) 161. 


\section{Figure captions}

Fig. 1. Experimental arrangement for fluorescence measurements.

Fig. 2. Ordinary fluorescence spectra for red dyes on silk under mercury lamp excitation $(\lambda=365 \mathrm{~nm})$. Maximum peak intensity ratios are as follows: sappanwood $(0.07)$, safflower (1).

Fig. 3. Fluorescence (a) and reflection (b) spectra of undyed silk cloth before (solid curve) and after exposure to intense light (dashed curve). Numbers are exposure time in hour.

Fig. 4. Same as Fig. 3 for sappanwood on silk cloth.

Fig. 5. Same as Fig. 3 for cochineal on silk cloth.

Fig. 6. Same as Fig. 3 for safflower on silk cloth.

Fig. 7. Same as Fig. 3 for Amur cork-tree on silk cloth.

Fig. 8. Same as Fig. 3 for turmeric on silk cloth.

Fig. 9. Same as Fig. 3 for gardenia on silk cloth.

Fig. 10. Same as Fig. 3 for kariyasu on silk cloth.

Fig. 11. Same as Fig. 3 for silk cloth dyed with a combination of sappanwood and yellow dyes: Amur cork-tree and turmeric.

Fig. 12. Same as Fig. 11 with a combination of safflower and yellow dyes: Amur cork-tree, turmeric and gardenia.

Fig. 13. Same as Fig. 11 with a combination of indigo and yellow dyes: Amur cork tree, kariyasu and gardenia. The reflection spectrum for indigo is indicated with the dotted curve. 
Table I. Natual dyes used in Japan.

\begin{tabular}{|c|c|c|c|c|}
\hline Dye & Scientific name & Pigment & Mordant & Colour on silk \\
\hline $\begin{array}{l}\text { Sappanwood } \\
\text { (chip) }\end{array}$ & $\begin{array}{l}\text { Caesalpinia } \\
\text { sappan }\end{array}$ & brazilin & $\begin{array}{l}\text { alum or } \\
\text { plant ash }\end{array}$ & red \\
\hline $\begin{array}{l}\text { Cochineal } \\
\text { (scale insect) }\end{array}$ & $\begin{array}{l}\text { Coccus } \\
\text { cacti }\end{array}$ & $\begin{array}{l}\text { carminic } \\
\text { acid }\end{array}$ & alum & red \\
\hline $\begin{array}{l}\text { Safflower } \\
\text { (flower head) }\end{array}$ & $\begin{array}{l}\text { Carthamus } \\
\text { tinctorius }\end{array}$ & carthamone & plant ash & red \\
\hline $\begin{array}{l}\text { Amur cork-tree } \\
\text { (inner bark) }\end{array}$ & $\begin{array}{l}\text { Phellodendron } \\
\text { amurense }\end{array}$ & berberine & disuse & yellow \\
\hline $\begin{array}{l}\text { Turmeric } \\
\text { (root) }\end{array}$ & Curcuma longa & curcumin & $\begin{array}{l}\text { citric acid or } \\
\text { plum vinegar }\end{array}$ & yellow \\
\hline $\begin{array}{l}\text { Gardenia } \\
\text { (fruit) }\end{array}$ & $\begin{array}{l}\text { Gardenia } \\
\text { jasminoides }\end{array}$ & crocin & $\begin{array}{l}\text { alum, plant ash } \\
\text { or disuse }\end{array}$ & yellow \\
\hline $\begin{array}{l}\text { Kariyasu } \\
\text { (whole grass) }\end{array}$ & $\begin{array}{l}\text { Miscanthus } \\
\text { tinctorius }\end{array}$ & $\begin{array}{l}\text { arthraxin and } \\
\text { luteolin }\end{array}$ & $\begin{array}{l}\text { alum or } \\
\text { plant ash }\end{array}$ & yellow \\
\hline $\begin{array}{l}\text { Indigo } \\
\text { (blade) }\end{array}$ & $\begin{array}{l}\text { Polygonum } \\
\text { tinctorium }\end{array}$ & indigo & disuse & blue \\
\hline $\begin{array}{l}\text { Shikon } \\
\text { (root) }\end{array}$ & $\begin{array}{l}\text { Lithospermum } \\
\text { erythrorhizon }\end{array}$ & shikonin & $\begin{array}{l}\text { alum or } \\
\text { plant ash }\end{array}$ & violet \\
\hline
\end{tabular}


Table II. Peak intensity ratio and peak wavelength of LIF

of undyed and dyed silk cloths before fading.

\begin{tabular}{lcc}
\hline & $\begin{array}{c}\text { Peak intensity } \\
\text { Dye }\end{array}$ & $\begin{array}{c}\text { Peak wavelength } \\
\text { ratio }\end{array}$ \\
\hline Undyed silk & 1 & 430 \\
Sappanwood & 0.07 & 650 \\
Cochineal & 0.03 & 640 \\
Safflower & 1 & 600 \\
Amur cork-tree & 3 & 540 \\
Turmeric & 2 & 530 \\
Gardenia & 0.1 & 520 \\
Kariyasu & 0.3 & 500 \\
Indigo & 0 & 500 \\
Shikon & 0.1 & 530 \\
Sappanwood + & 0.8 & 500 \\
Andigo + Peak intensity ratio is a ratio of fluorescence intensity at peak \\
wavelength for each dye or undyed silk to that for safflower. \\
Andigo +
\end{tabular}


Table III. Colour difference of undyed and dyed silk cloths after fading.

\begin{tabular}{|c|c|c|}
\hline Dye & $\begin{array}{c}\text { Exposure time } \\
\text { (h) }\end{array}$ & $\begin{array}{l}\text { CIE colour } \\
\text { difference } \\
\text { value } \Delta \mathrm{E}\end{array}$ \\
\hline Undyed silk & 52 & 10.1 \\
\hline \multirow[t]{3}{*}{ Sappanwood } & 44 & 25.2 \\
\hline & 52 & 32.3 \\
\hline & 74 & 37.0 \\
\hline Cochineal & 74 & 13.4 \\
\hline \multirow[t]{3}{*}{ Safflower } & 8 & 29.0 \\
\hline & 20 & 37.6 \\
\hline & 44 & 47.9 \\
\hline \multirow[t]{2}{*}{ Amur cork-tree } & 5 & 13.6 \\
\hline & 52 & 25.2 \\
\hline \multirow[t]{3}{*}{ Turmeric } & 1.5 & 19.4 \\
\hline & 3 & 25.6 \\
\hline & 12 & 33.1 \\
\hline Gardenia & 74 & 16.6 \\
\hline Kariyasu & 52 & 9.4 \\
\hline
\end{tabular}


Fig. 1

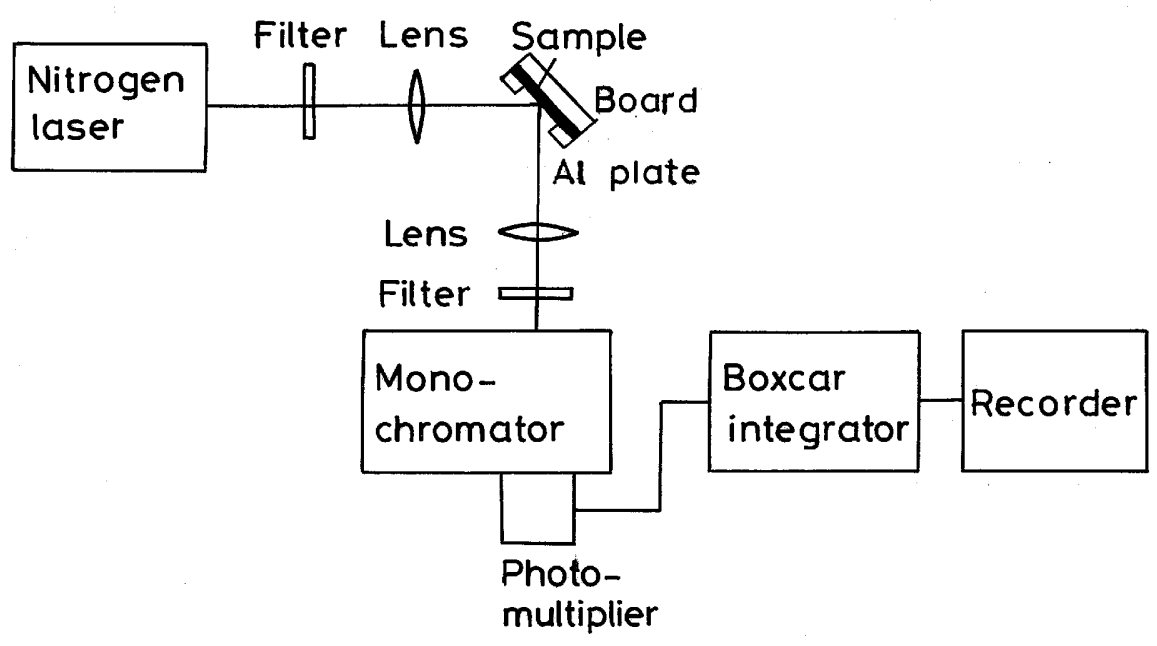

Fig. 2

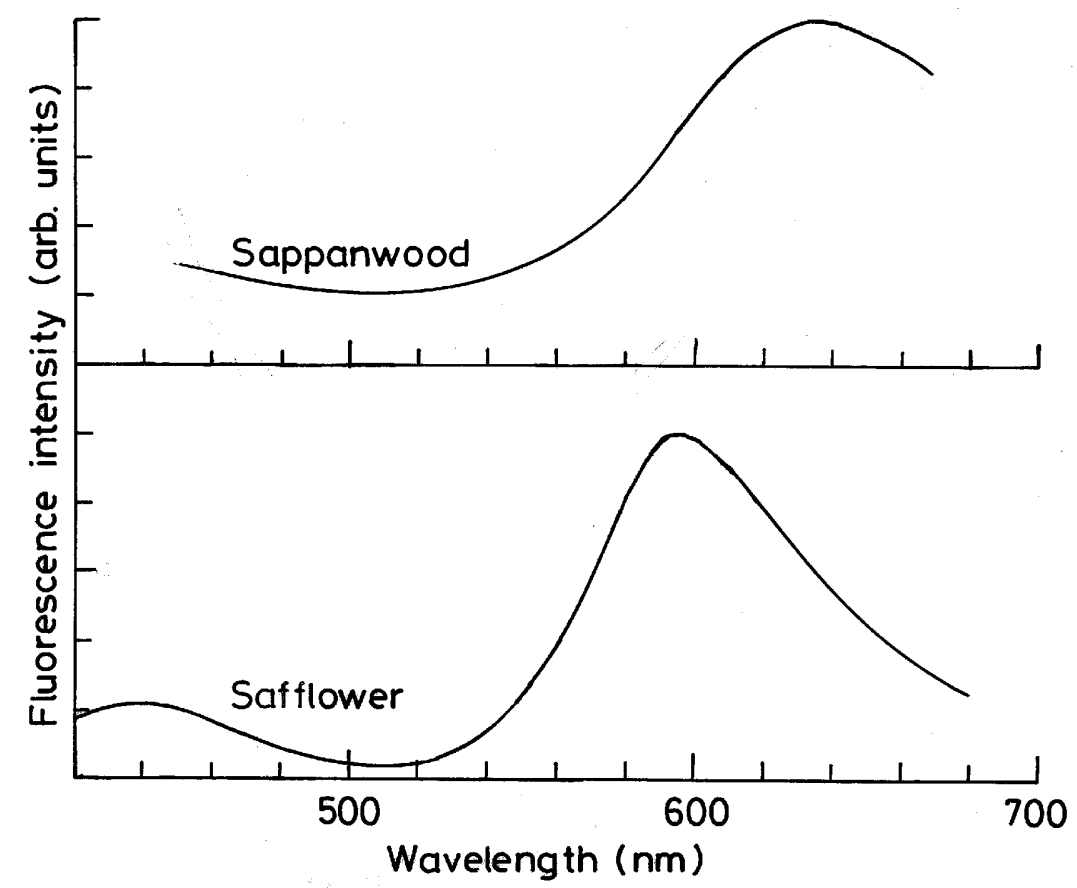


Fig. 3
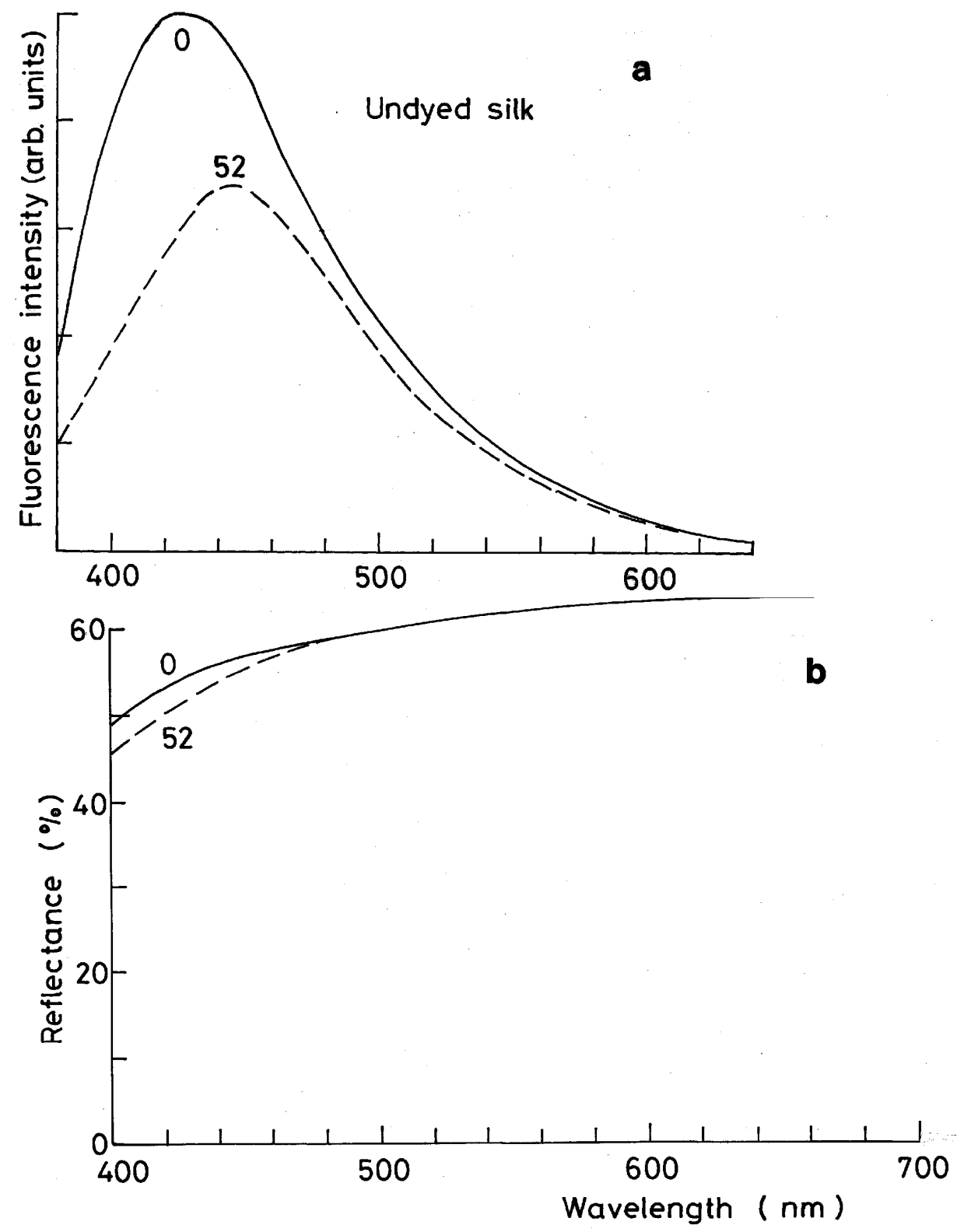
Fig. 4
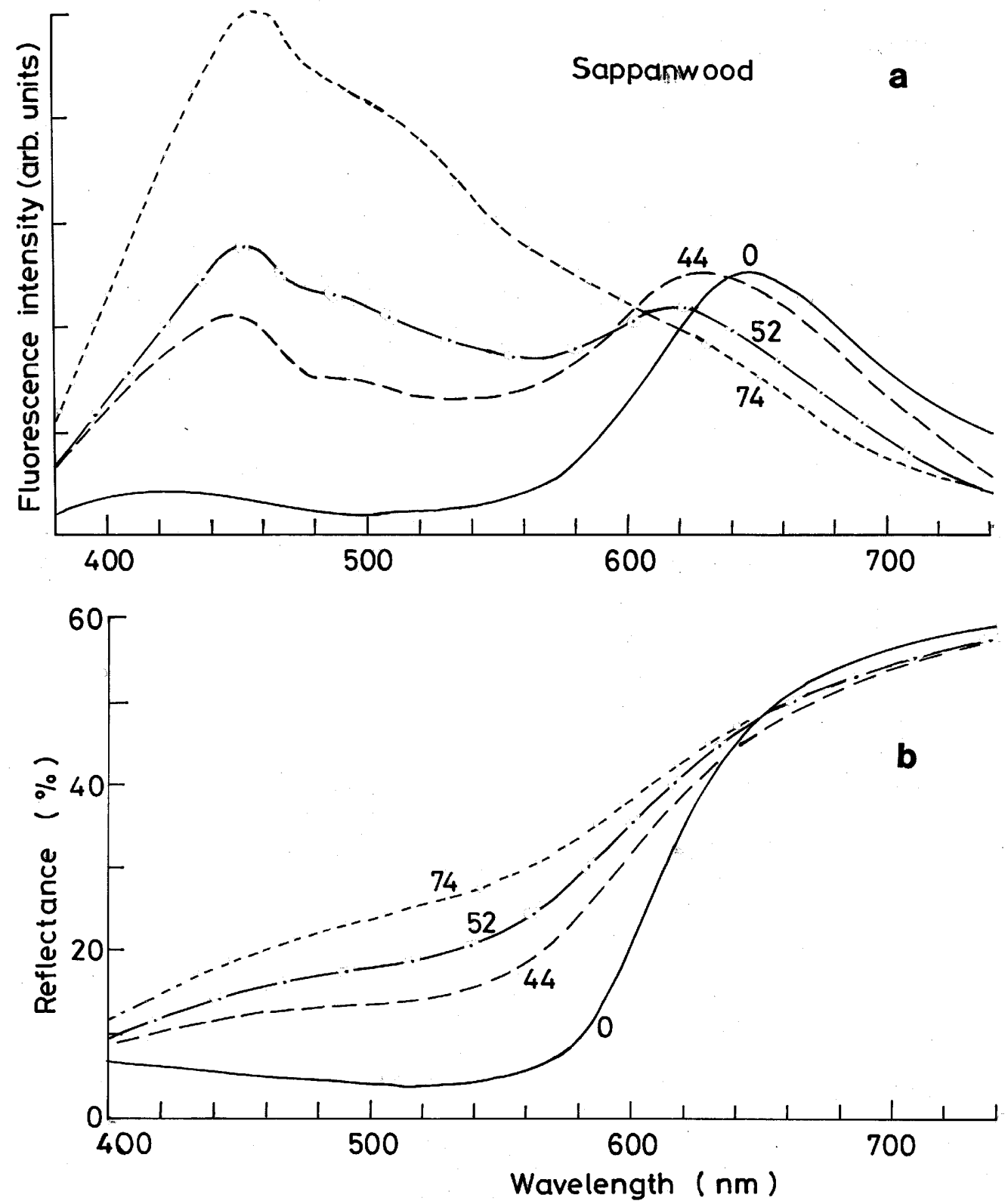
Fig. 5
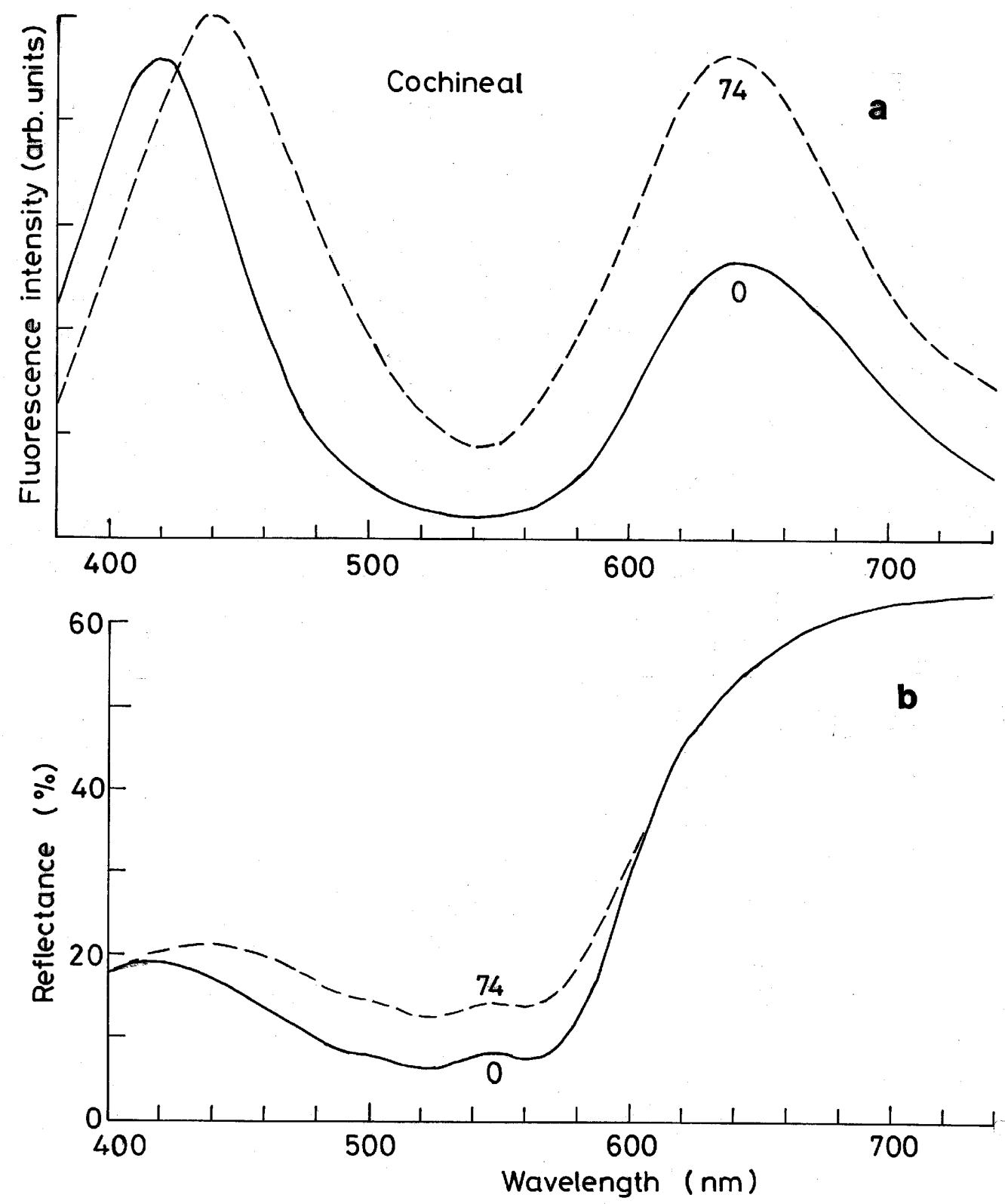
Fig. 6
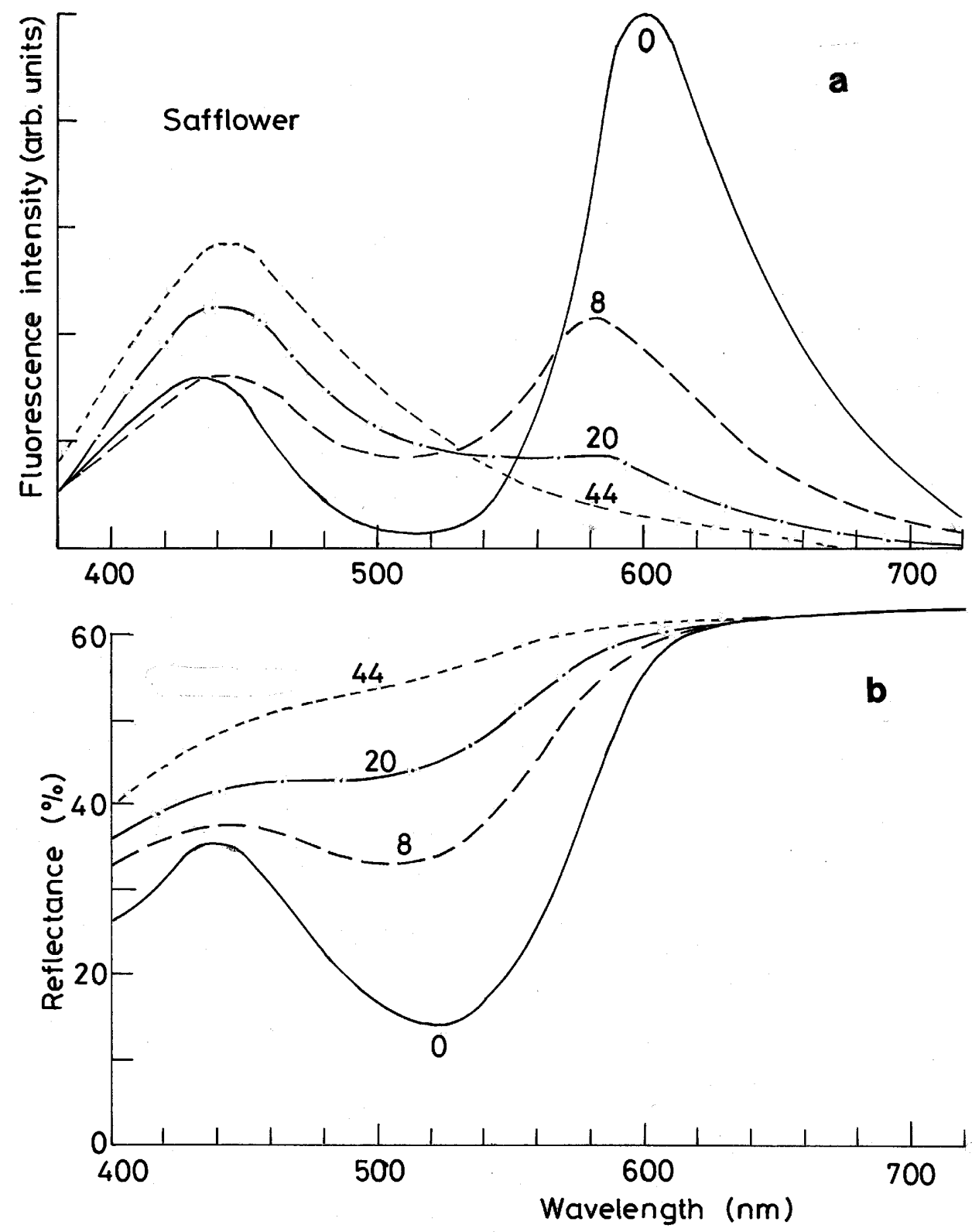
Fig. 7
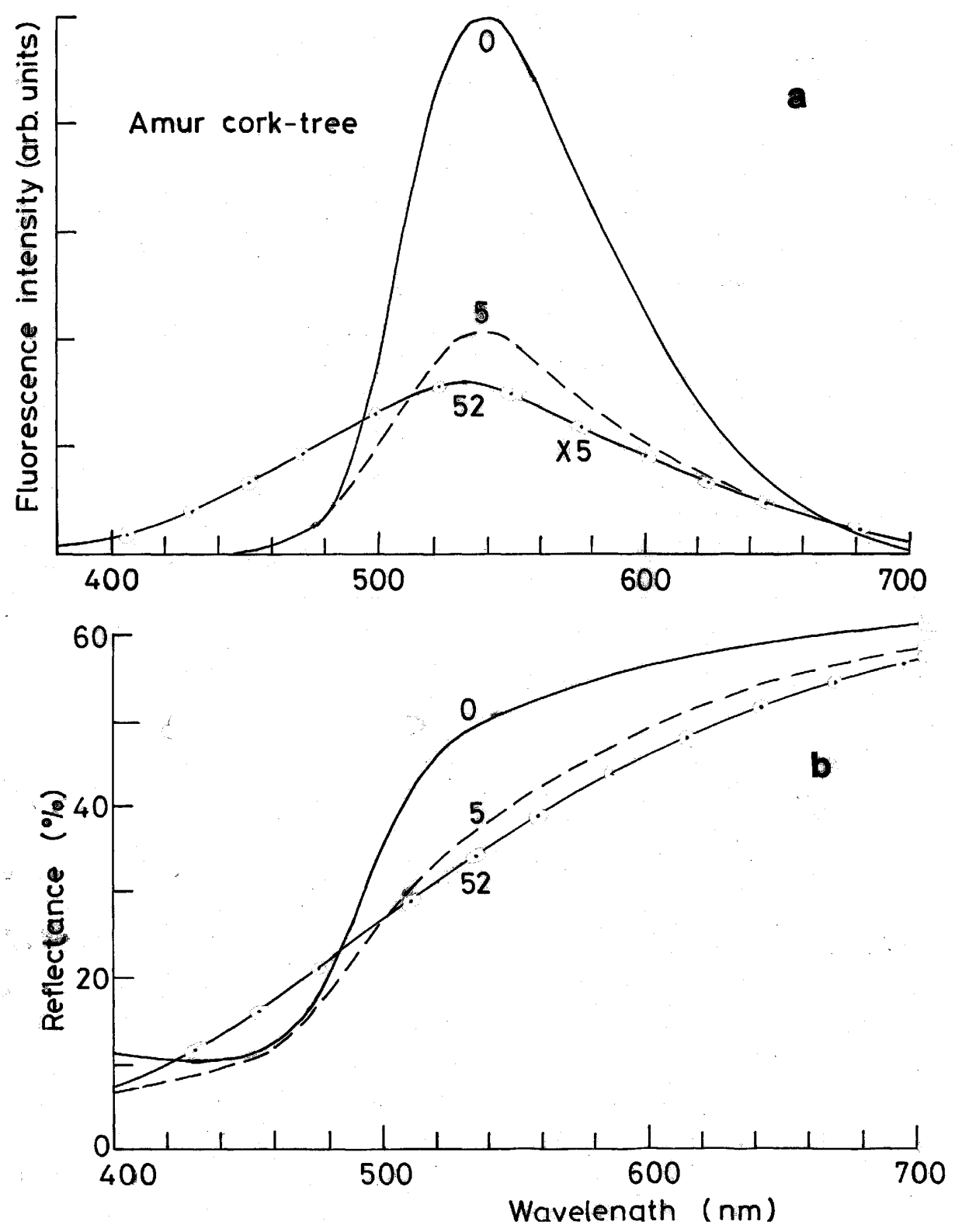
Fig. 8
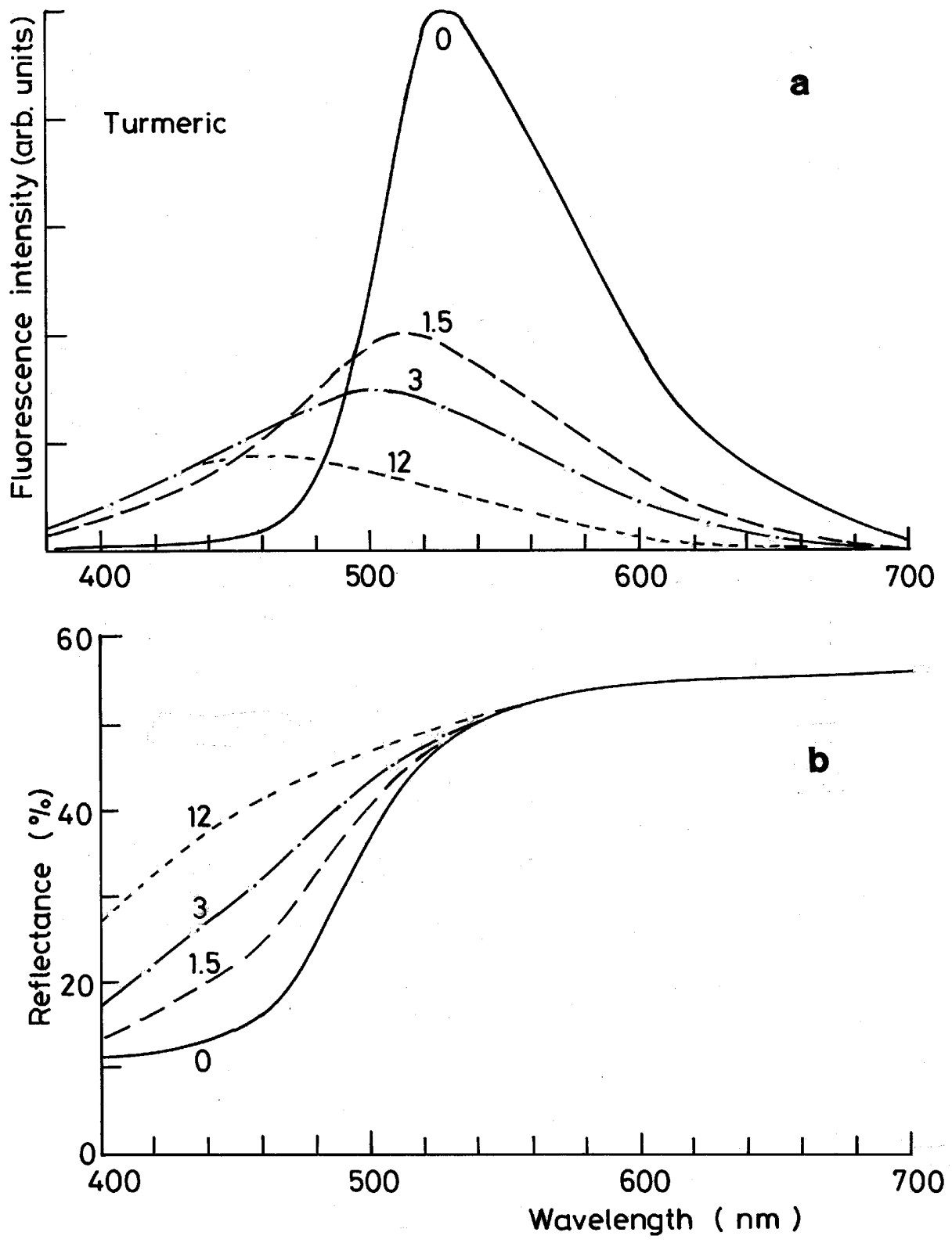
Fig. 9
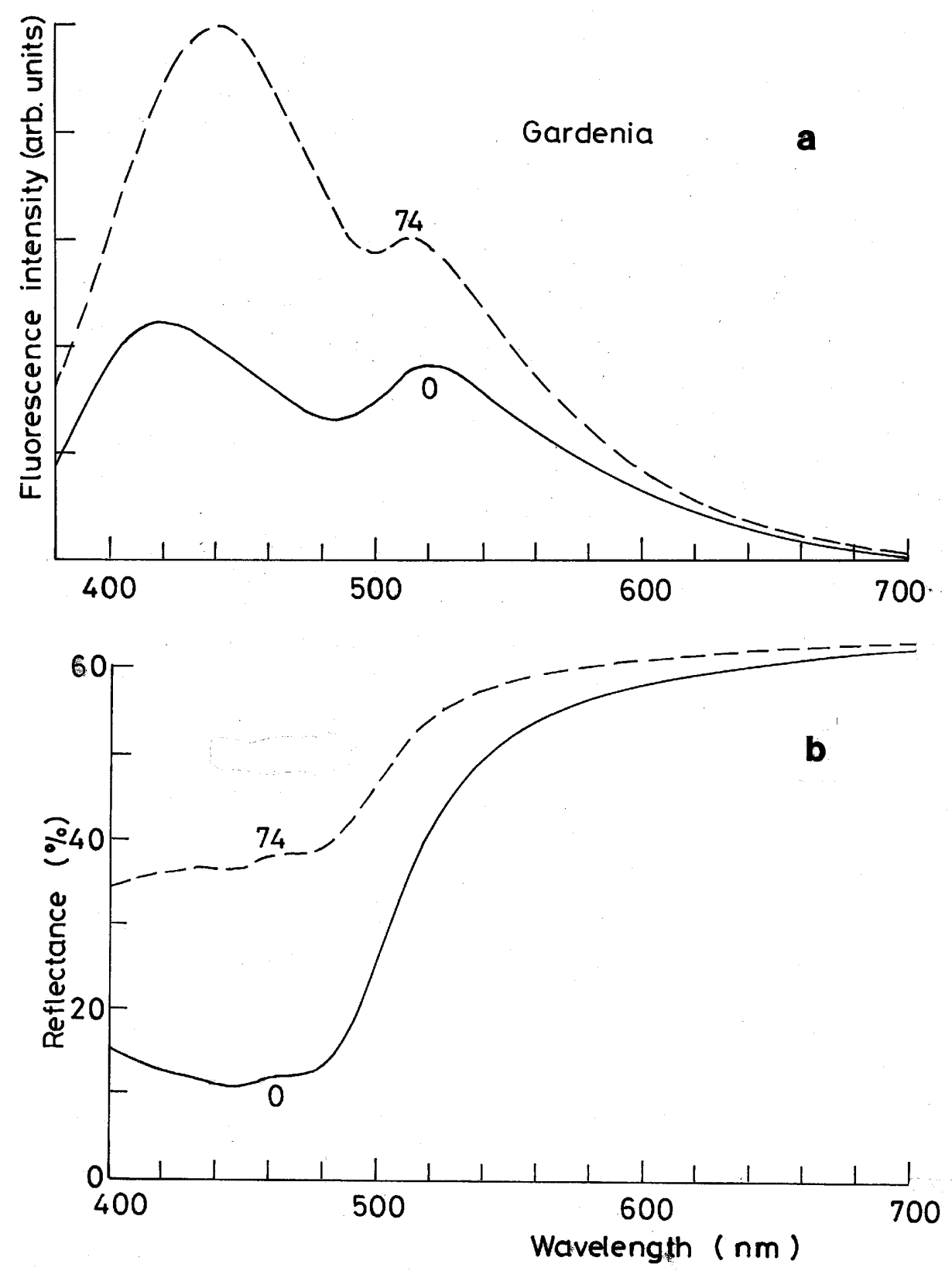
Fig. 10
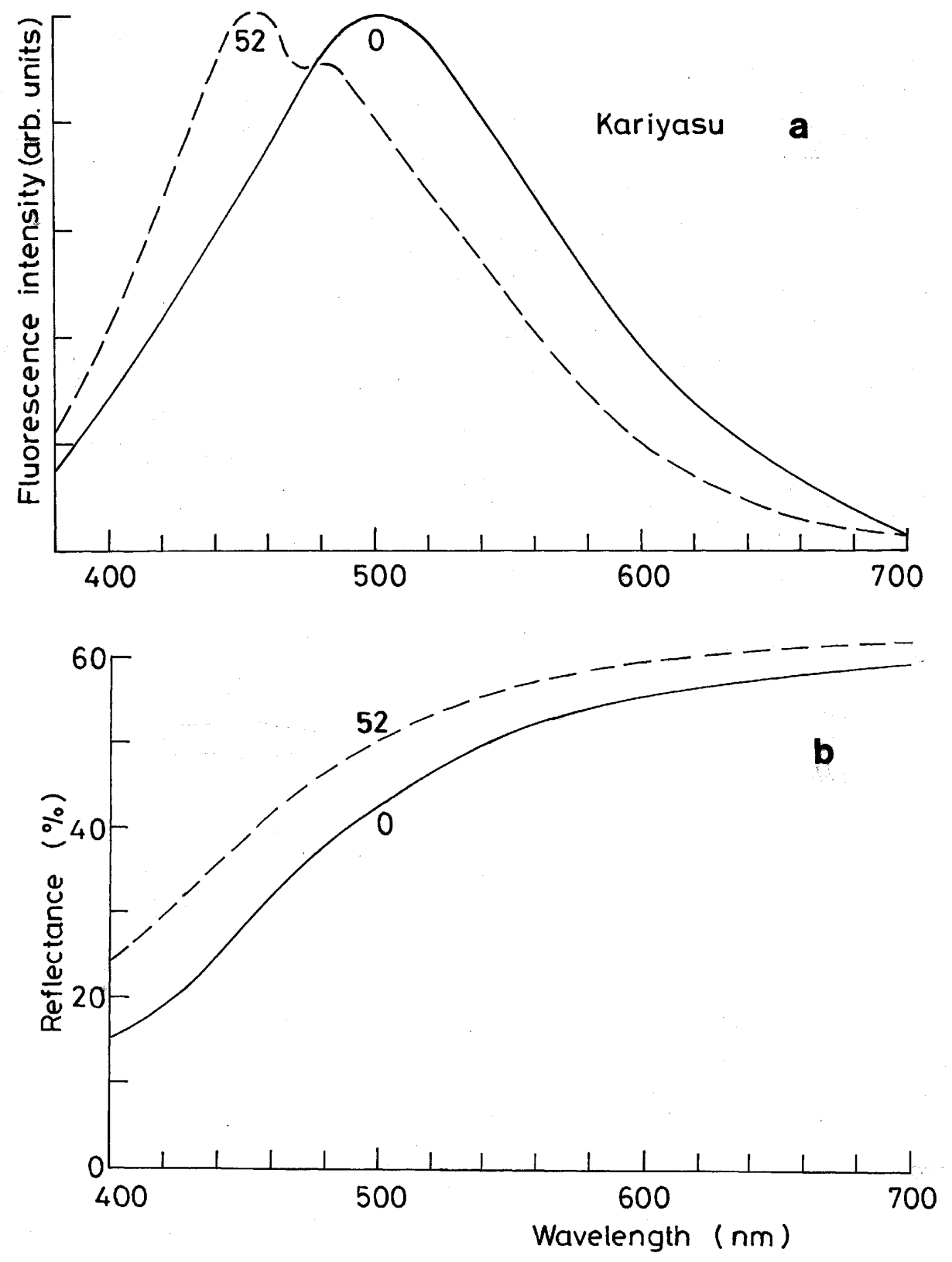
Fig. 11
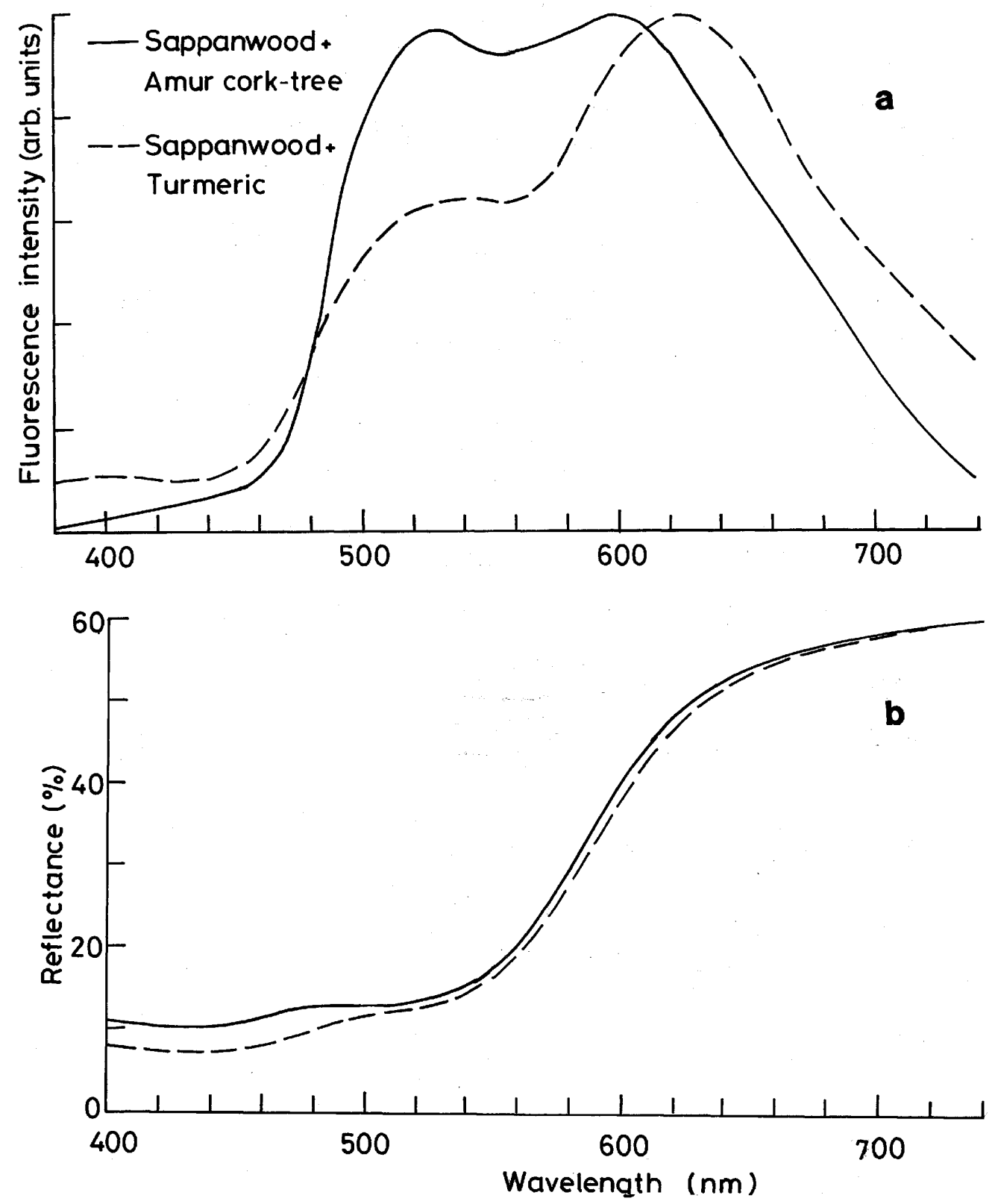
Fig. 12
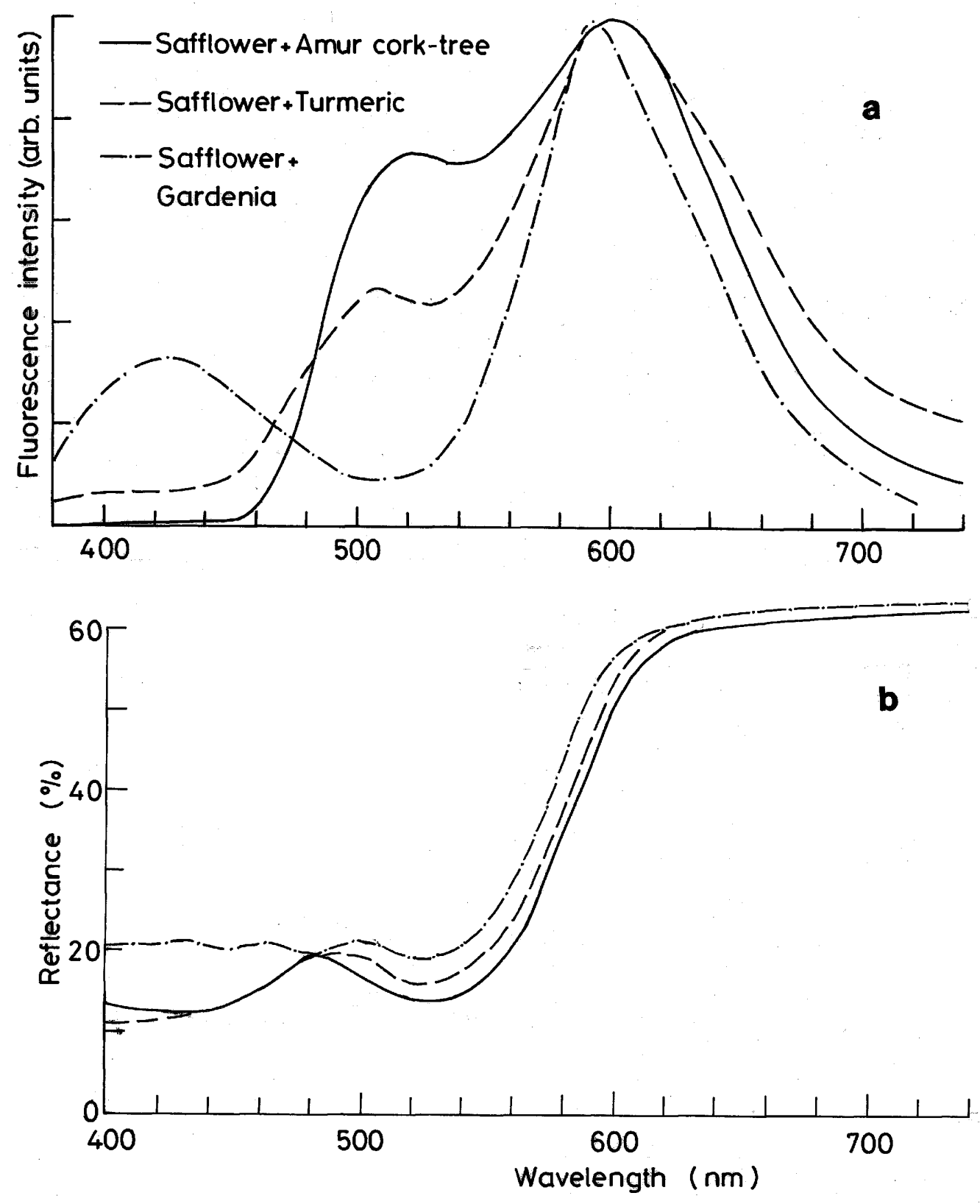
Fig. 13
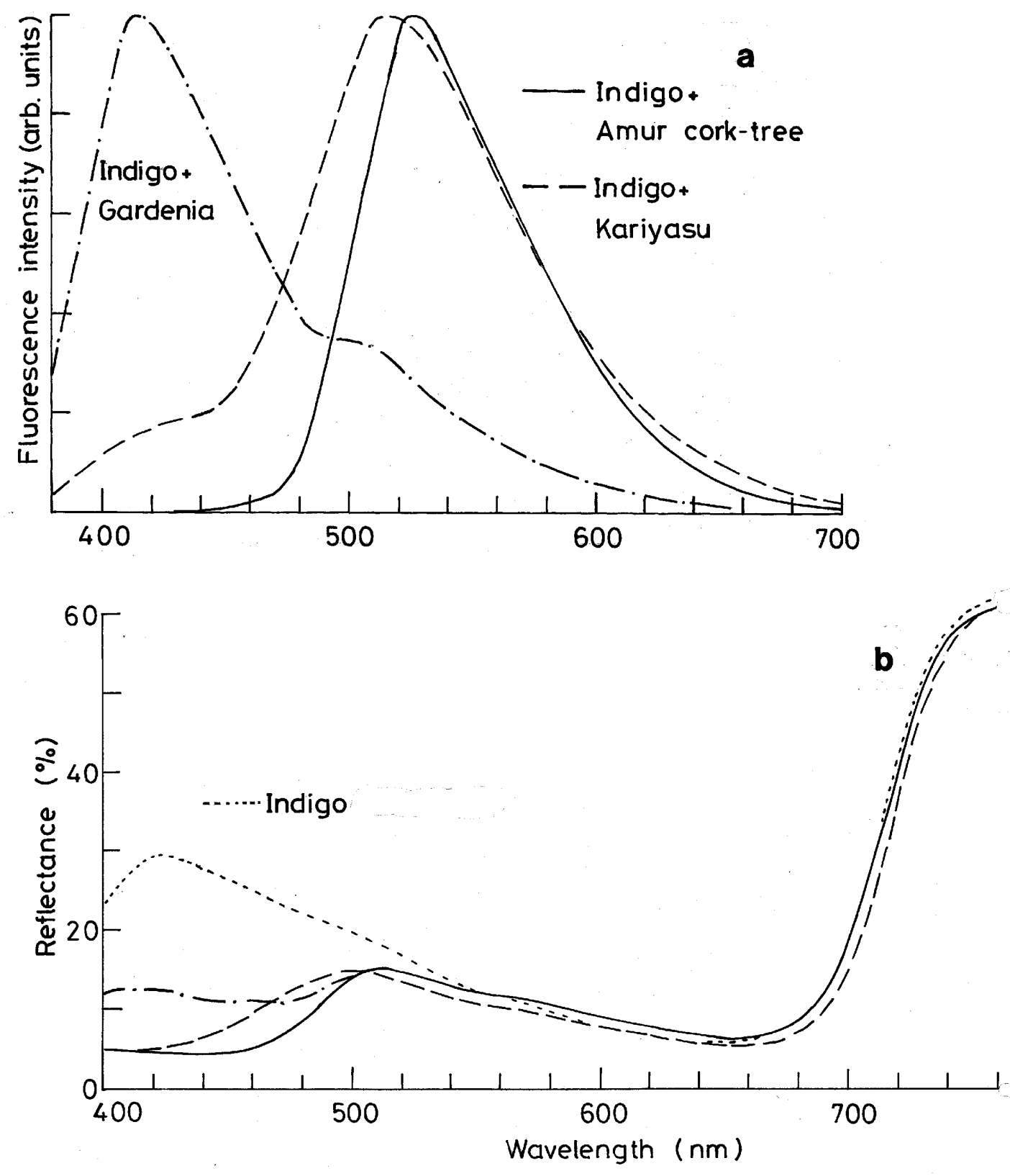